NISTIR 7989

\title{
Maturity Model Concepts for Sustainable Manufacturing
}

\author{
Sanjay Jain \\ Sudarsan Rachuri
}

http://dx.doi.org/10.6028/NIST.IR.7989 


\title{
Maturity Model Concepts for Sustainable Manufacturing
}

\author{
Sanjay Jain \\ The George Washington University \\ Washington, $D C$
}

Sudarsan Rachuri

Systems Integration Division

Engineering Laboratory

http://dx.doi.org/10.6028/NIST.IR.7989

March 2014

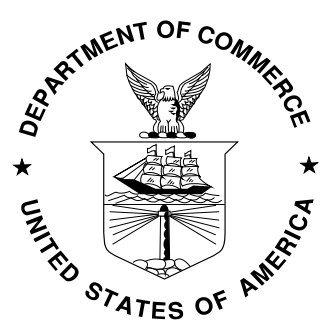

U.S. Department of Commerce

Penny Pritzker, Secretary

National Institute of Standards and Technology Patrick D. Gallagher, Under Secretary of Commerce for Standards and Technology and Director 


\section{Maturity Model Concepts for Sustainable Manufacturing}

\section{Abstract:}

Sustainability has been identified as an emerging business megatrend that companies across the spectrum need to respond to. Companies in the manufacturing industry have also increased their efforts in this direction. However, the efforts for improving the efficiency of manufacturing processes vary widely across the industry and may vary even within different locations of a large manufacturing organization. This paper reviews major initiatives and research relevant to developing and providing guidance for organizations interested in sustainable manufacturing. A concept is proposed for a maturity model to assist manufacturers with understanding the status of their efforts for sustainable manufacturing specifically focusing on materials, energy, and water use. The concept is being presented to gather inputs from relevant stakeholders and for further development into a model that provides high-level guidance to manufacturers for improving sustainability of their operations.

\section{INTRODUCTION}

Sustainability has been identified as an emerging business megatrend that companies need to address to stay competitive and maybe, to even survive (Lubin and Esty, 2010). There are efforts across the globe to implement green manufacturing and achieve sustainable manufacturing (Dornfeld, 2014). It has been pointed out that "if current patterns of consumption continue, it is estimated that global resource use will quadruple within 20 years" (European Commission, 2008). Many organizations have mounted initiatives to utilize resources more efficiently in their operations. Examples in office environments include reduced printing of documents via increased use of on-line business processes and minor changes in indoor temperature settings for reduced energy for climate control. Examples in the manufacturing industry include reduction of sheet material requirements through better layout of part shapes on the sheets, better designs that lead to reduced packaging materials, and collapsible pallets that are reused for shipping products. Such efforts generally appear to be carried out in an ad hoc manner and driven by individual organizations and at times at individual locations within an organization. Industry needs guidance on common measures for measuring the impact of sustainability programs and benchmarks to gauge their progress (KPMG, 2011).

A concept for a maturity model is proposed in this paper with the objective of providing high level guidance to manufacturers for sustainable manufacturing efforts. Maturity models can be a vehicle to encourage organizations to achieve higher levels of performance (Saco 2008). Generally maturity models include a number of maturity levels, where a maturity level can be defined as an evolutionary plateau of process improvement (CMU, 2002). The model provides the criteria for an organization to determine the level they are at and select direction for improvement based on the criteria for the next higher level. 
The proposed sustainable manufacturing maturity model (SMMM or SM3) in this paper can be developed and used by manufacturers to assess the status of their efforts and to help establish goals for continued progress in sustainable manufacturing. Interested manufacturers with performance measurement systems in place that are compliant with applicable standards can initiate collection of proposed indicators while the concept is further developed and adopted by relevant industry associations.

The envisaged path from the proposed concept to the sustainable manufacturing maturity model includes gathering input from stakeholders, in particular from manufacturers and organizations representing their interests, and making needed modifications to produce a validated and effective structure. The model can then be further customized to specific industry groups with the addition of domain-specific information.

The target audience for a sustainable manufacturing maturity model comprises manufacturing decision makers, analysts, and advisors with interest in improving the sustainability of their operations. The model is particularly targeted at small and medium enterprises (SMEs) which may not have the resources to mount large data collection efforts to generate a number of indicators. The goal is to assist SMEs in their endeavor to improve sustainability of their manufacturing operations. This has prompted us to limit the number of indicators used for the specified assessments.

The immediate need is for a model focused on a manufacturing plant. It will help though if the scope of the model accommodates manufacturing operations distributed across multiple locations. The above scope does not include use of life cycle management and assessment tools as called for in an earlier proposal for a maturity model by Mani, Lyons, and Sriram (2010). The concept proposed in this paper is focused on the efficient use of material, energy, and water in manufacturing operations and does not consider other phases of the product life cycle. This is in alignment with Smith and Ball (2012) who focused on material, energy, and waste flows in a manufacturing facility for improving sustainable manufacturing. This model is also in alignment with Senge, Carstedt, and Porter (2001) who noted that the focus for sustainable development in manufacturing is usually on resource efficiency. The scope is similar to that of the production efficiency dimension of sustainability identified by the Resource Efficient and Cleaner Production (RECP) program, a joint program of the United Nations Industrial Development Organization (UNIDO) and United Nations Environment Programme (UNEP, 2010). UNEP will be delivering a list of key environmental indicators for decision-making in business and government by 2015 (UNSCD, 2012) that may be considered for integration in SM3 in the future.

As the scope is manufacturing operations, the model assesses the progress towards sustainability using indicators, systems, and procedures commonly used in a manufacturing plant. One concern may be raised that the focus on plant level indicators in some cases may have consequences that reduce the efficiency of the overall supply chain. The supply chain partners should be able to identify such cases and develop mutually beneficial arrangements in the interest of the overall supply chain efficiency. Also, comparisons with other industry peers can help identify such cases. 
Sustainable manufacturing performance has been identified as originating from the plant floor (Zhang and Haapala, 2014). Manufacturers should first focus their efforts to implement sustainable manufacturing at the plant level. Once the manufacturers have developed the capability at the plant level, they can then address the more complex issue of improving sustainability at the level of supply chains. The complexity in improving sustainability at the supply chain level is due to technical challenges emanating from a large number of involved parameters affecting sustainability indicators. The complexity is also due to business challenges emanating from volatility of markets and the independence of supply chain partners with their own priorities and development visions. Manufactures may be involved in multiple supply chains and might receive multiple conflicting inputs from different supply chain partners and hence may have to make decisions in the interest of optimization of their own operations.

The supply chain level considerations have been raised in a number of other efforts, some of which are discussed in the next section. EPA (2006) discusses defining boundaries for manufacturing operations as part of guidance on life cycle assessment (LCA). The report discusses cases where an extended scope beyond immediate manufacturing operations should be considered. It should be noted that parallel to not including supply chain considerations, it is recommended that the concept for manufacturing sustainability maturity model not include LCA indicators. However, the knowledge generated from LCA of products manufactured at the facility should be used to the extent possible to address any identified issues at the manufacturing stage. Improving manufacturing sustainability will help a corporation to improve the overall corporate sustainability. Van Marrewijk (2003) reported that corporate sustainability is considered to include corporate social responsibility (CSR) as a subset by some and as synonymous with CSR by others. Similarly some authors include the consideration of environmental, economic, and social aspects as part of CSR while others consider CSR to focus on only the social aspects. This paper focuses sustainable manufacturing on reduction of use of resources with near term impact on the environmental and economic aspects and long term impact on the social aspects. Sustainable manufacturing can thus be seen as contributing to CSR. Consolandi et al. (2009) reported that "the evaluation of the CSR performance of a firm is a significant criterion for asset allocation activities." Thus sustainable manufacturing can indirectly contribute to a company improving its performance on stock markets. It is believed that the immediate need is for a quick assessment tool that can help identify general directions, priorities, and goals for improvement in sustainable manufacturing. Once the directions and goals have been determined other more detailed tools, some of which are referenced in section 2, can be used for developing and evaluating improvement strategies and tactics. The strategies and tactics that are validated through models can then be implemented in real manufacturing system and monitored. The model will thus form a part of an overall continuous improvement methodology described in Jain et al. (2013).

The literature provides two similar constructs for assessment, maturity models and maturity grids. Maier, Moultrie, and Clarkson (2012) point out that maturity grids and maturity models are quite similar in structure and are composed of maturity levels and key performance factors. While admitting that it is difficult to differentiate between the two, they suggest that maturity grids are applicable to any industry and any process while maturity models are for specific processes and domains. Per their definition, the 
proposed concept can be classified as a precursor for a maturity model due to its focus on the manufacturing domain.

Maturity models and grids have been used in a wide range of fields for assessment of organizational capabilities and process improvement efforts. The pioneering use of maturity grids was proposed by Crosby (1979) for assessing quality management practices in an organization. The Software Engineering Institute of Carnegie Mellon has been credited with developing the first successful maturity model, the Capability Maturity Model for software development (Weyns and Höst, 2012). Maier, Moultrie, and Clarkson (2012) present 24 maturity grids aimed at a wide range of organization capabilities including safety, energy, research and development, project management, and teamwork.

This section provided the motivation and goals for developing a maturity model for sustainable manufacturing. The next section reviews relevant literature. Section 3 presents the proposed concept for the maturity model, and section 4 discusses research and implementation challenges. Section 5 concludes the report.

\section{LITERATURE REVIEW}

A majority of the research efforts in sustainable manufacturing have focused on a high level view of manufacturing and include the three dimensions of sustainability, that is, economic, environmental, and social. Smith and Ball (2012) point out that the efforts have generally focused on product life cycle and discussed issues of product development, use, and disposal, with few providing guidance for improvements at the manufacturing stage specifically.

In this section, developments that provide guidance for improving manufacturing sustainability are reviewed. While an effort has been made to identify the developments relevant to the scope of this paper, it is possible that some may have been missed given the rapid growth of literature on topics related to sustainable manufacturing. Per Maier, Moultrie, and Clarkson (2012), developing a maturity grid involves identification of relevant process areas and associated maturity levels. The review of developments relevant to assessing sustainable manufacturing will help identify the key process areas and factors considered. In the interest of simplicity to promote wider application, limited process areas should be proposed for consideration preferably combined into one set for ease of assessment by SMEs.

Our review of literature covers the following:

- Relevant guidance

- Relevant ISO standards

- Recommended strategies and practices

- Indicators and metrics

\subsection{Relevant Guidance}

This sub-section reviews efforts that provide guidance for improving sustainability. The areas addressed in these efforts have been considered for inclusion in the proposed maturity model directly or as part of a sustainability performance factor. 
Ceres (2010) provides guidance for moving entire organizations towards sustainability. This guidance defines multiple expectations under the categories: Governance for Sustainability, Stakeholder Engagement, Disclosure, and Performance. The Performance category is further organized into the following sub-categories: operations, supply chain, transportation and logistics, products and services, and employees. The key expectations under operations are reproduced below as they are relevant to our selected manufacturing scope:

"1. Greenhouse Gas Emissions and Energy Efficiency: Companies will reduce greenhouse gas emissions by $25 \%$ from their 2005 baseline by 2020:

- Improving energy efficiency of operations by at least $50 \%$

- Reducing electricity demand by at least $15 \%$

- Obtaining at least $30 \%$ of energy from renewable sources

2. Facilities and Buildings: Companies will ensure that at least $50 \%$ of their owned or leased facilities, and all new construction, will meet rigorous green building standards. When siting facilities, companies will follow best practices that incorporate sustainable land-use and smart growth considerations.

3. Water Management: Companies will assess water-related impacts and risks and will set targets to improve water use and wastewater discharge, with priority given to operations in water stressed regions.

4. Eliminate Waste: Companies will design (or redesign, as appropriate) manufacturing and business processes as closed-loop systems, reducing toxic air emissions and hazardous and nonhazardous waste to zero.

5. Human Rights: Companies will regularly assess key risks related to human rights throughout their entire operations, and will employ management systems that are aligned with internal policies and support the implementation."

The Global Reporting Initiative (GRI, 2013) has recently released the fourth generation (G4) of its sustainability reporting framework. Its intent is to have companies and organizations use a standard approach for their sustainability reporting with information on economic, environmental, social, and governance performance. The standard approach permits disclosure at multiple levels and allows comparison across organizations. Also, regular reporting supports decision makers in creating and tracking long term strategies for improving sustainability. The G4 release also provides links with related efforts including the Organisation for Economic Cooperation and Development (OECD) guidelines for multinational enterprises, United Nations global compact "ten principles," and UN guiding principles on business and human rights. In addition, linkage documents are provided for use of the GRI framework with a number of other standards. The disclosures included in the GRI framework that are relevant for our defined scope of material, energy, and water are listed below.

- Materials 
- Materials used by weight or volume.

- Percentage of materials used that are recycled input materials.

- Energy

- Direct energy consumption by primary energy source.

- Indirect energy consumption by primary source.

- Energy saved due to conservation and efficiency improvements.

- Initiatives to provide energy-efficient or renewable energy based products and services, and reductions in energy requirements as a result of these initiatives.

- Initiatives to reduce indirect energy consumption and reductions achieved.

- Water

- Total water withdrawal by source.

- Water sources significantly affected by withdrawal of water.

- Percentage and total volume of water recycled and reused.

The UNEP/SETAC (Society of Environmental Toxicology and Chemistry) life-cycle management capability maturity model (LCM-CMM) (Validivia 2012) defines four levels: qualified, efficient, effective, and adaptive with the corresponding boundaries identified as project, enterprise, value chain, and society respectively. It should be noted that the term "value chain" is used to define boundaries same as that of the supply chain for products but with an emphasis on the value provided to the end customer. Initial sustainability efforts may be limited to projects, and as the organization matures, they expand to the enterprise and beyond. With our scope focused on manufacturing facilities, the first two levels are relevant to our effort. The model utilizes the following indicators at the first two levels:

- Compliance and process outputs (at "Qualified" level)

- Process inputs, outputs, and eco-efficiency (at "Efficient" level)

World Resources Institute (WRI) and World Business Council for Sustainable Development (WBCSD) have developed a protocol for the calculation of emissions of greenhouse gases (GHG) over a product life cycle (WRI/WBCSD 2011). The scope includes material acquisition \& pre-processing, production, distribution \& storage, use, and end-of-life for a product. For the production stage, the recommended method includes collection of data on material inputs and outputs, energy used, and emissions for each process. Guidance is provided on defining boundaries, ensuring quality of data, defining uncertainty, and calculating an "inventory" of GHG emissions. The basic data collection of materials and energy inputs at the production stage is the same as in our proposed concept. WBCSD has also developed tools to assist organizations with their efforts to improve sustainability. The Global Water Tool (GWT) helps companies assess their water use and associated risks in their global operations (Finley, Leathers, and Zhang 2008). WBCSD and Global Environmental Management Initiative (GEMI) developed a Local Water Tool (LWT) that integrates with GWT and helps companies assess and manage water related issues at specific sites (GEMI, 2012).

The Organisation for Economic Co-operation and Development (OECD) has developed a toolkit for sustainable manufacturing focused on SMEs that includes 18 indicators across inputs, operations, and products (OECD, 2011). The toolkit focuses on production activities in a facility, proposes starting with 
monitoring and improving on a few of the suggested indicators, and recommends that an SME add more as the maturity increases. The indicators relevant to our focus include the following.

- Materials indicators

- Non-renewable materials intensity.

- Restricted substances intensity.

- Residuals intensity.

- Energy indicators

- Energy intensity.

- Water indicators

- Water intensity.

The "intensity" is used as a way to normalize the value of indicators by presenting them per specific unit of output. Different factors are recommended for use as unit of output including number or weight of products produced, sales or value added in the facility, and person-hours worked in the facility. The determination may be made based on which factors are used by benchmarking peers or by the relevant industry or trade association. The toolkit also recommends using industry peers as benchmarks for setting and achieving realistic targets.

The American National Standard Institute (ANSI), working through the Institute for Market Transformation to Sustainability (MTS), created consensus standards for sustainable products in 2006 (MTS, 2006). The standards utilize a Sustainable/Environmentally Preferable Purchasing (EPP) Product Supply Chain Achievement Matrix that can be used by manufacturers to calculate scores for their sustainability progress. As a company moves up the levels, it earns points that are then used to calculate a total score. The matrix defines six levels across five attributes. The three attributes relevant to our scope together with the specified abbreviations by ANSI are: Renewable Energy \& Energy Reduction (RE\&ER), Bio-based or Recycled (MATLS), and Facility or Company Based (MFG). Compared to some of the other efforts that call for improved energy and material efficiency, this standard provides credits for use of renewable energy and bio-based materials in addition to the reduction of energy and material. Hence, a company that has achieved the same reduction in energy and material use as another, but has replaced some of the energy used with renewable energy and/or replaced some of the materials used with bio-based materials will earn a higher achievement score. The MFG attribute scoring is based on use of policy, procedures and systems in the manufacturing facility for environmental measurements and disclosures.

Level 1 for RE\&ER and MATLS requires capturing the base energy and material content inventory respectively. Higher scores are achieved based on percentage reduction and/or percentage increase in use of renewable energy and bio-based materials compared to the level 1 inventory. Higher scores beyond defined thresholds lead to achieving higher levels. The standard refers to several other existing standards to ensure consistency in measurements. While the approach of percentage improvements against one's own established baseline takes away the issue of identifying industry benchmarks, it makes performance comparison across different industries difficult since larger percentage improvements may be achieved with the same or less effort in one industry versus the other. 
The standard BS 8900-1:2013 from the British Standards Institution (2013) recommends the use of a sustainable development maturity matrix to help organizations determine their position along a sustainable development path. The matrix is provided as a guideline allowing organizations to customize it for their unique situation. The provided example framework in the standard document is arranged to allow an organization to define the stages identifying increasing maturity for practices that implement a set of principles. The recommended minimum principles include: inclusivity, integrity, stewardship, and transparency. Provided examples utilize three to four stages from minimum involvement to full engagement. An organization can define additional or alternate principles for setting up the matrix for their use. The recommended principles, in particular, integrity and transparency are definitely needed for all efforts including for the maturity model concept presented later in this paper.

The Underwriters Laboratories has developed the UL880, a sustainability standard targeted at large and medium size manufacturing organizations (UL, 2011). It considers the domains of governance for sustainability, environment, work force, customers and suppliers, and community engagement and human rights. The standard defines prerequisites, core indicators, and leadership indicators in each of the domains that are considered for certification. The standard considers the following factors related to our proposed scope:

- Energy: GHG Inventory Scope 1 and 2 that includes identifying energy consumption and sources, energy (and GHG) management program, reduction targets and performance.

- Water: Water use inventory, water (and wastewater) use efficiency and reduction plans, targets and performance.

- Material: Waste inventory, reduction management program, targets and performance.

The Industrial Research Institute released a Sustainability Maturity Assessment Tool (IRI, 2012), that utilizes questions with "yes-no" answers distributed in 14 key categories. It includes the following questions relevant to our proposed scope in the overall sustainability strategy category:

- "Do your plants or manufacturing facilities track energy or water usage?"

- "Does your company invest in alternative energy use, water reuse, and carbon-neutral technologies?"

Also, relevant questions in the Design for Environment (DFE) - manufacturing category include:

- "Has the company begun to assess the environmental impacts of the manufacturing processes and options?"

- "Has the company begun to taking steps to reduce waste/ energy consumption?"

A majority of the questions in the DFE-manufacturing category focus on environmental impact and thus, indirectly address the material, energy, and water use.

Reefke, Sundaram, and Ahmed (2010) present a maturity model for sustainable supply chains. The model has six levels with the first four levels focused on compliance going from "unaware and noncompliant" at level one to "linked and exceeds compliance" at level four. Level five is achieved when 
sustainability is fully integrated and proactive measures are taken towards further improvement. Level six is achieved when the organization provides sustainability leadership across the supply chain. A sustainability modeling and reporting (SMART) system is presented that utilizes system dynamics models for analysis and a dashboard that shows current, industry benchmark, and target numbers for selected indicators. The authors do not discuss specifics for manufacturing nodes in the supply chain. The proposed concept in this paper utilizes elements of their approach including the use of compliance at lower levels and continuous improvements at higher levels to assess maturity and the use of industry benchmarks to help set the targets.

Cagnin and Loveridge (2011) present a five level business sustainable maturity model with the levels indicating process maturity across seven value activities. "Operations" is included as one of the values activity. The first four levels - ad-hoc, planned in isolation, managed with no integration, and excellence at corporate level - focus on the organization level and the fifth level, high performance sustainability net, focuses on the supply network. While most of the levels are process improvement focused, the second level includes better use of materials and natural resources, and the fourth level includes use of renewable energy resources and fewer natural resources.

Manufacturing Enterprise Solutions Association (MESA, 2010) presents a five level manufacturing maturity model that assesses maturity across five business domains: strategy, processes, structure, people, and information technology (IT). The maturity model is used to support development of manufacturing transformation strategy. A working group at MESA is currently engaged in developing a metrics maturity model that assesses maturity of deployment of performance measurement processes and systems (MESA, 2014). The metrics maturity model is anticipated to include recommended metrics at successive levels of maturity for various aspects of manufacturing including sustainability (Horst, 2014).

It is clear that a number of initiatives have already developed and yet others are in progress that are developing guidance on aspects to consider, metrics, and levels of maturity for sustainability, with specific guidance for manufacturing operations in some cases. The downside of having the range of initiatives is that a SME looking for guidance can be easily overwhelmed. There have been efforts to identify correspondence among some of the initiatives but that still leaves a large number of options for consideration for a SME that is looking to improve sustainability aspects of its manufacturing operations. It will help to have a simple model to get SMEs initiated in this process without overwhelming them. As they mature based on a simple model, they will be in a better position to discern among the options available should they decide to embrace more complex models.

\subsection{Relevant ISO Standards}

The International Organization for Standardization (ISO) provides standards covering a wide range of topics including the assessments of sustainability indicators. Maturity models utilize assessments on defined indicators. The assessments have to be carried out in a consistent manner to allow comparison across organizations and in particular to benchmarks. Consistency in assessments can be ensured through the use of applicable standards. ISO has the following standards relevant to the defined scope of the proposed concept for a sustainable manufacturing maturity model: 
- ISO 14001:2004 Environmental Management Systems - Specification With Guidance for Use

- ISO 14004:2004 Environmental Management Systems - General Guidelines on Principles, Systems and Supporting Techniques

- ISO 14005:2010 Environmental management systems - Guidelines for the phased implementation of an environmental management system, including the use of environmental performance evaluation

- ISO 14031:1999 Environmental Management - Environmental Performance Evaluation Guidelines

- ISO 14051:2011 Environmental Management - Material Flow Cost Accounting - General Framework

- ISO 19011:2002 Guidelines for quality and/or environmental management systems auditing

The ISO 14000 series of standards are aimed at helping organizations implement environmental management systems (EMS). It should be noted that the standards do not specify indicators or performance levels for sustainable development. Rather, the standards provide guidance for the implementation of management systems for defining the goals and measurement systems for aspects of an organization's operations that may have an impact on the environment. The standards do provide examples of indicators that can be used. ISO 14031 provides guidelines for indicators for environmental performance and environmental conditions. The environmental performance indicators are defined as being of two types: operational and management. Provided examples of operational performance indicators (OPIs) include quantity of water used per unit of production, and quantity of raw materials reused in the production process. Provided examples of management performance indicators (MPIs) include number of products with explicit "product stewardship" plans, and number of products designed for disassembly, recycling or reuse. The OPIs are relevant for the effort reported in this paper given their focus on manufacturing operations.

The listed standards include relevant information for measurements of materials, energy, and water usage in manufacturing. In particular, ISO 14051 discusses tracking the flow of materials and the allocation of energy and system costs to storage areas and process steps identified generically as "quantity centers." While the purpose of ISO 14051 is to provide a framework for cost accounting, the steps used to track the flow of materials are useful for capturing all material flows in and out of the facility. The proposed indicators in this paper are based on the entire facility; however, the material flows for quantity center will be useful for the next level analysis if the maturity model analysis points to low material efficiency.

Other standards in 14000 series have not been included in the list provided in this section to keep the focus on the scope of the proposed concept for a sustainable manufacturing maturity model. For example, the ISO 14006 provides guidelines of managing eco-design of products within the EMS but the scope of eco-design includes the environmental impact across the product lifecycle and hence, is not included. Use of procedures in accordance with the above selected standards will provide credible assessments of status and progress towards sustainable manufacturing. 
The above list of standards may appear daunting to a manufacturer, particularly an SME, interested in sustainable manufacturing. The SMEs are encouraged to utilize the phased implementation approach for EMS provided in ISO 14005 together with informative examples. In addition, the European Commission (2007) provides a guide for SMEs to implement Eco-Management and Audit Scheme (EMAS) and to continue on to implement ISO 14001 with a highly focused effort. Manufacturers should initially focus on implementing an EMS for tracking information specific to the selected indicators. As the manufacturers get more mature in their use of standards, they can expand to using additional indicators and increasing the scope of application of the selected indicators (e.g., from one assembly line to multiple lines and then to entire plant). The use of standard indicators will ensure credibility and the ability to compare the indicators across locations and across organizations.

\subsection{Recommended Strategies and Practices}

Rashid, Evans, and Longhurst (2008) present and compare four strategies for sustainable manufacturing. They explain that the four strategies are hierarchical in nature, with the scope increasing in the following order: waste minimization, material efficiency, resource efficiency, and eco-efficiency. The strategies become more qualitative going up the hierarchy, and the sustainability progress becomes complicated to measure. The authors indicate that the selection of strategy will depend on the involved practitioner and their past manufacturing experience but highlight that material efficiency is at the core of sustainable manufacturing and should not be neglected in favor of energy efficiency.

Hiller, Mills, and Reyna (2011) provide findings from a survey conducted by Environmental Defense Fund (EDF) Climate Corps host companies. EDF's Climate Corps program matches graduate students from leading institutions with interested companies where the students act as change agents for energy management. The findings on leading practices for energy management, all of which are applicable for manufacturing, include:

“Organization priority: Greenhouse gas reduction goals, centralized energy management, benchmarking energy performance

Access to capital: tracking of efficiency investments, including NPV (Net Present Value) in financial requirements, dedicated funding for efficiency projects

Information Collection: mandatory reporting and data tracking, sub-metering and EMS

External factors: Leases that favor energy efficiency, financial decisions account for energy prices, sustained commitment to energy efficiency"

IGEL (2012) focuses on greening of the supply chain (i.e., using sustainable practices across the supply chain) and recommends use of enterprise resource planning software for tracking hazardous material, water and electricity use, waste produced, etc. The recommended practices relate to supply chains, including two practices that are applicable widely for manufacturing: "put your effort where it will do the most good," and "collaborate to innovate." The report suggests that compliance with "green" (i.e., environmental) regulations can over time help organizations progress along the maturity path of "compliance, obligation, efficiency and leadership." 


\subsection{Indicators and Metrics}

The terms "indicators" and "metrics" have been used with different definitions in literature. Sikdar (2003) states "metrics are more popularly known as indicators." Others take the view that indicators and metrics are closely related yet are different. This paper aligns with the latter view and utilizes the definitions provided by Fiskel, Eason, and Frederickson (2012). They differentiate between indicators that they define as "a summary measure that provides information on the state of, or change in, the system that is being measured" and a metric that is defined as "the measured value(s) used to assess specific indicators." Per their definition "mass of mercury emitted per unit of energy delivered" is an indicator while its units "grams of mercury per kilowatt-hour" are the associated metric.

A large number of indicators and metrics have been suggested in the context of sustainable manufacturing in a number of publications. There are also survey efforts that have reviewed and collected the indicators and metrics. First an example is provided of a publication that defines a number of metrics for sustainability assessment of steel production facilities. Next, the desirable characteristics of indicators per selected existing literature are discussed. Finally, the results of a recent effort that surveyed the available peer-reviewed literature are utilized to extract indicators suitable for the concept proposed in this paper.

Singh (2008) utilizes Analytic Hierarchy Process (AHP) for developing a composite sustainability index for steel production that combines indexes and metrics for organizational governance, technical aspects, economic performance, environment performance, and social performance. While the author used the terms "indexes," and "metrics," the terms "indicators" and "metrics" could have been used per the definition provided at the beginning of this section. The technical aspects and environment performance metrics used by Singh (2008) are listed in Table 1.

Singh (2008) proposed the set of indexes and metrics for use in steel industry. Graedel and Allenby (2002) support the use of a common metric to compare the environmental performance of corporations in the same industrial sector. They also support the use of a common metric to track the performance of a single corporation over time.

Sikdar (2003) grouped performance indicators for sustainability based on the three aspects: ecological, economic, and sociological. He further classified the indicators as one, two, or three dimensional based on their assessment of individual aspect, intersection of two and three aspects respectively. Two dimensional indicators assess intersection of two aspects, that is, eco-efficiency, socio-ecological, and socio-economic, while three dimensional indicators assess all three dimensions together. For assessing the sustainability of businesses and processes, Sikdar (2003) points out that the chosen indicators should be small in number and as independent of each other as possible. He recommended the use of three-dimensional indicators first followed by use of two and one dimensional indicators if needed for further delving into details. He identified energy use, material use, and pollutant dispersion as threedimensional indicators since they can have ecological impact, have associated economic costs, and can have direct or indirect impact on human population. He classified water use as a one or twodimensional indicator addressing economic and ecological aspects. Given the water scarcity issues that have risen over the decade since his publication and their impact on human population, water use 
should now be considered as a three-dimensional indicator. Also, among the three indicators identified by him, pollutant dispersion may be a difficult one to measure particularly for SMEs due to potential additional equipment and expertise required.

Table 1. Metrics included by Singh (2008).

\begin{tabular}{|l|l|}
\hline Technical Aspects & Environmental \\
\hline Coke rate (Kg/thm) & Particulate matter stack emission load (Kg/tcs) \\
\hline Blast furnace productivity & Percent utilization of total solid wastes (\%) \\
\hline Labor productivity & Specific energy consumption (Gcal/tcs) \\
\hline Export tonnage ratio & Specific raw material Consumption (tonnes/tcs) \\
\hline Defects (\%) & Specific water consumption (m3/tcs) \\
\hline Special grades production (\% of saleable steel) & Specific carbon dioxide emissions (kg/tcs) \\
\hline New product development (\% of saleable steel) & Specific effluent load (kg/tcs) \\
\hline $\begin{array}{l}\text { Market performance (\% increase in domestic share } \\
\text { with prev. year) }\end{array}$ & Specific refrigerant consumption (kg/tcs) \\
\hline Customer satisfaction Index & Specific power consumption (Kwh/tcs) \\
\hline $\begin{array}{l}\text { Savings through suggestions \& QC projects } \\
\text { (Rs/tcs) }\end{array}$ & Specific refractory consumption (kg/tcs) \\
\hline Cost reduction (Rs/tcs) & Percentage green cover of total plant area (\%) \\
\hline Equipment availability (\%) & Specific hazardous waste generation (kg/tcs) \\
\hline Order compliance (\%) & Specific heavy metals discharge load (kg/tcs) \\
\hline No. of complaints & Average noise level in the periphery of plant (dB) \\
\hline & Overall average opacity (\%) \\
\hline
\end{tabular}

(Units: kg - Kilograms; thm - ton of hot metal; tcs - ton of crude steel; Gcal - Giga calories; Rs - Indian Rupees; Refractory materials include minerals such as bauxite, magnesia, and graphite. that are consumed during steel production; Opacity is the amount of light obscured by particulate matter in the emissions)

Fiskel, Eason, and Frederickson (2012) describe a framework of sustainability indicators developed at the U.S. Environmental Protection Agency. They surveyed a large number of peer reviewed efforts to create a database of sustainability indicators and indices (DOSII) with 1411 entries. One of the classification schemes utilized for the entries is scale with five levels: global, national, regional, community, and industrial.

The DOSII was filtered to identify 216 indicators with the scale defined as "industrial" aligned with the scope of the proposed concept. Aligned with recommendations of Sikdar (2003), the 216 indicators were reviewed with the objective of identifying a few selected three-dimensional indicators relevant to the selected scope for the proposed concept. Table 2 shows the two summary indicators that were extracted from the industrial scale group and a third indicator proposed in a manner parallel to the first two.

Table 2. Proposed indicators for use with the proposed concept

\begin{tabular}{|l|l|l|l|l|}
\hline No. & Indicator name & Source & Description & Example metric \\
\hline 1 & Energy intensity & $\begin{array}{l}\text { Krajnc and Glavic } \\
(2003)\end{array}$ & $\begin{array}{l}\text { Total energy consumed/Value of } \\
\text { product sold or Value added }\end{array}$ & Joules/\$ \\
\hline 2 & Material intensity & $\begin{array}{l}\text { Krajnc and Glavic } \\
(2003)\end{array}$ & $\begin{array}{l}\text { Total material input mass/Value of } \\
\text { product sold or Value added }\end{array}$ & $\mathrm{Kg} / \$$ \\
\hline 3 & Water intensity & $\begin{array}{l}\text { Proposed in this } \\
\text { paper }\end{array}$ & $\begin{array}{l}\text { Total fresh water used/Value of } \\
\text { product sold or Value added }\end{array}$ & Cubic meters/\$ \\
\hline
\end{tabular}


It should be noted that the original source, Krajnc and Glavic (2003), defined the value added in Euros but we have modified the monetary units to dollars. Krajnc and Glavic (2003) define an indicator for water usage as water cost fraction to be calculated as total water costs/total production costs. However, the use of water intensity as defined above provides a consistent structure, in addition to providing a mechanism to normalize all the indicators by value added. Also, the material intensity does not include energy carriers (fuels, coal, etc.) and water in the calculation of total material input parallel to the practice advised in EMAS (European Commission, 2009). European Commission (2004) provides guidelines for measurement of energy consumption for use by SMEs and for improving energy efficiency. A model applicable to all sectors of manufacturing should be developed using the indicators in Table 2. The selection of associated metrics should be done by industry organizations for specific domains such as plastics molding, casting, automotive components, and semiconductor manufacturing.

It was mentioned earlier that the ISO 14000 series of standards do not define standard performance measures and levels. However, section A.3.1 in the appendix to ISO 14001:2004 provides examples of "environmental aspects" that are measures relevant to environmental performance. The examples include "use of raw materials and natural resources," "use of energy," and "waste and by-products," that are related to the proposed three indicators for use in the maturity model. Further, the note to section 3.18 of ISO 14001:2004 indicates that efficient use of resources can be one way of preventing pollution and thus reducing the environmental impact of the organization's activity. Similarly, as mentioned earlier ISO 14031:1999 provides examples of OPIs that include those related to energy, material, and water use. The proposed indicators are hence in alignment with the relevant ISO standards.

Indicators for the consumption of the three resources (materials, energy, and water) are called for in multiple efforts such as the GRI framework (GRI, 2013), the eco-efficiency measurement framework (WBCSD, 2000), and the product life cycle accounting and reporting standard (WRI/WBCSD, 2011). A company that is following one of these frameworks can thus utilize the proposed concept of maturity model in this paper with minimal additional effort.

\section{PROPOSED CONCEPT FOR A MATURITY MODEL}

The goal of our proposed concept for a maturity model is to provide a high level assessment tool for the status of sustainable manufacturing efforts. It should not require a large effort to generate the high level assessment as that may discourage its use, particularly by SMEs. It should provide credible assessments that can be compared across manufacturing locations and across companies. These major desired characteristics prompted us to propose the following criteria in developing the concept:

- Include standard approaches for measurements that are used in the assessment of maturity

- Include a few selected indicators for the assessment rather than a large multitude of indicators

Elements of the approach proposed here are similar to those in some of the maturity assessment efforts discussed in section 2 . In particular, a structure is suggested that emphasizes compliance and 
establishing a standard approach to baseline the status at lower levels and progress on selected indicators at higher levels. This is similar to the structures used by ANSI MTS (2006) and Reefke, Sundaram, and Ahmed (2010). The idea of using compliance at the initial level is also similar to the idea of prerequisites in UL880 standard (UL, 2013). These three identified efforts, ANSI MTS (2006), Reefke, Sundaram, and Ahmed (2010), and UL880 standard (UL, 2013), have wider scope than the proposed model. Also, similar to ANSI MTS (2006), it is suggested that existing standards be utilized to assess compliance at the lower levels rather than creation of new measurement procedures. Use of existing standards will also help gain correspondence with other efforts that have referred to the same standards. For example, the GRI framework $(G R I, 2013)$ has developed documents defining linkages with ISO standards.

The proposed concept assesses maturity based on performance as judged with selected indicators rather than process characteristics. A model that can support all of manufacturing based on the maturity of manufacturing processes may be difficult to achieve due to the variety across the wide range of domains within manufacturing. Admittedly, the proposed use of compliance to standards at the lower maturity levels does indirectly assess use of some processes. However, the compliance in this case is to measurement processes for selected metrics and not to any standardized manufacturing processes. A concern may be raised that an organization may achieve the reported performance temporarily using ad hoc processes. This concern is addressed through the use of moving targets at higher maturity levels in the proposed concept. An organization cannot achieve the performance year after year using ad hoc processes and will have to establish mature processes for consistent performance. The focus on performance measures over time thus indirectly encourages maturity of manufacturing and operations processes leading to consistent performance.

The proposed concept for a sustainable manufacturing maturity model may be used to conduct factory level assessments to gauge the current sustainability performance against a set of defined levels and determine the improvement opportunities using the next level of maturity as the target. The proposed concept is presented in Figure 1. Level 0 is the base level. Levels I and II assess the ability of organization to capture standard indicators for energy and water use and material efficiency. Levels III and IV assess and guide the factory's journey to improved sustainability by comparing the indicators with those of best in class in the associated industry group. Each of these levels is discussed in more detail below. Again, the model should be defined using indicators with the associated metrics being selected for specific domains within manufacturing by associated industry organizations.

SM3 Level 0 "Initial." The default status for a large number of companies is business as usual with no specific activities for improving sustainability, including no specific activities for improving resource efficiency, that is, to reduce input materials, energy, and water relative to the outputs. Many manufacturers have been motivated by competitive pressures to implement efforts such as lean manufacturing or have had to reduce energy consumptions to drive cost down. While such ad hoc efforts may have made quantifiable improvements, the measurement procedures used may not be standard or comparable, and thus, the collected indicators are hard to compare against other similar manufacturers. There may be limited organizational awareness and/or support for implementing systems for tracking indicators for resource efficiency. 


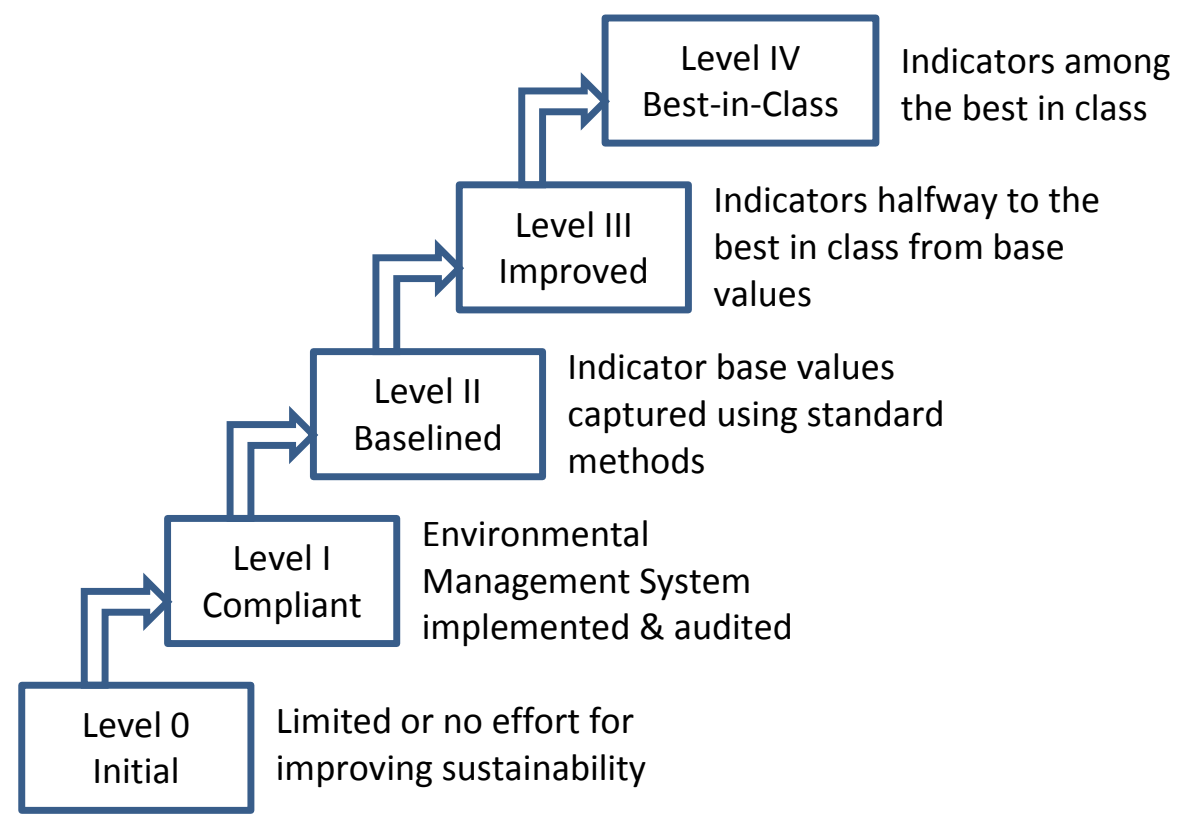

Figure 1. Proposed Concept for a Sustainability Manufacturing Maturity Model (SM3).

SM3 Level I "Compliant." This level is focused on voluntary compliance. ISO standards (ISO14001/4/5) define implementation of EMS and the assurance of a proper implementation through auditing. Another ISO standard (ISO14031) evaluates environmental performance of management systems. Voluntary compliance with these ISO standards will ensure that the manufacturer has the management infrastructure in place for collecting credible data that can be used to generate indicators of interest for the assessment of maturity. The EMS implementation should be audited following the guidance from the ISO 19011:2002 standard. Pojasek (2007) suggests that EMS implementation and maintenance efforts should be integrated with other efforts such as quality and safety for receiving higher value from the initiative. In fact, ISO 14001:2004/Cor.1:2009 provides a table documenting the correspondence between its elements and the elements of ISO 9001:2008 that describes quality management systems to demonstrate that the two systems can be used together. While use of ISO standards is recommended, industry organizations may elect to identify other standards that they consider more relevant to their domain.

SM3 Level II "Baselined." This level is focused on capturing existing performance using the defined indicators of sustainable manufacturing to serve as the baseline for quantifying future improvements. The measurements should be made following standard approaches from relevant ISO standards (ISO14031 and ISO 14051). The ISO 14031 standard provides the standard terminology for sustainable manufacturing performance indicators. The ISO 14051 standard provides guidelines for material flow cost accounting to capture the use of materials, energy, and losses in both physical and monetary terms and thus supports calculation of the three indicators defined in section 2.4. While we recommend the three indicators, the list of indicators and standards for guidance should be finalized with input from organizations that work on issues relevant to the entire manufacturing sector. Again, industry 
organizations should then define specific metrics corresponding to selected indicators and perhaps augment the list of standards for use in their domains.

SM3 Level III "Improved." This level identifies the manufacturers who have made substantial progress towards sustainable manufacturing. It requires first identifying best in class performance on the selected indicators achieved by other manufacturers. Further, it requires identifying the gap between the manufacturer's baseline performance and the best in class performance, determining and implementing ways to improve the performance on the selected measures, and confirming that the manufacturer has progressed at least halfway on each of the indicators towards achieving the best in class performance. The challenge of identifying the best in class performance is discussed in the next section. A manufacturer will be rated at level III after having achieved an audited performance at the halfway mark between its own base line performance and the best in class performance. It should be noted that by design this is a moving target. A manufacturer who achieves level III and then gets complacent may fall below the level since the best in class performance is expected to continually improve. A manufacturer may have to continually improve performance on the selected measures just to stay at level III. The initial improvements in selected indicators may be achieved by focusing on policies and procedures within the manufacturing facilities. The product and process design may be treated as fixed constraints. The focus at this level may be on process operation parameters to improve the selected indicators. Such improvements may include adjustments to machine settings, and implementation of lean manufacturing practices. It is anticipated that the improvements that raise the manufacturer to level III will result in efficiencies and cost savings that can then be utilized for investments for further progress in sustainability.

SM3 Level IV "Best-in-Class." This level recognizes the manufacturers who have achieved the best in class performance. Again, the challenge of identifying best in class performance is discussed in the next section. Best-in-class may be identified based on ranges of indicators for material, energy, and water usage as it will be difficult to achieve the highest values across all the indicators for one manufacturer. Alternate approaches should be considered with input from the manufacturing industry and other stakeholders. For example, a composite index combining the three indicators (or other number of indicators selected with input from manufacturing industry) may be used with flexibility provided for weightages to be adjusted by industry organizations for specific domains. Again, this will continue to be a moving target as different manufacturers in the identified class will continue improving and hence it will not allow any manufacturer who has achieved level IV to become complacent. It is anticipated that manufacturers will have to make deeper efforts to move to level IV. Such deeper efforts may require making changes in product and process designs that lead to improvements in the selected indicators for manufacturing operations. For example, a material change for a component may allow use of a process that uses less energy, material and water. Manufacturers may also need to utilize information from LCA of products manufactured at the facility to address identified issues with product design and manufacturing.

With the proposed concept, a manufacturer may use the maturity model internally up to level II. To move to level III, the manufacturer will need to identify the best in class and that requires identification of a group of similar manufacturers. Such a group may be identified through trade associations or 
through consortia. Trade associations and consortia may coordinate collection and sharing of information of indicators within the identified group. Arrangements may be made to share the information anonymously without linking company names to actual indicators thus encouraging participation. Best-in-class companies and perhaps even level III may identify themselves to take due credit for their efforts in achieving the maturity and reap the benefits from associated customer goodwill.

The motivation behind the proposal to utilize the best in class performance as targets is multi-fold. As stated earlier, it prevents manufacturers from getting complacent given the moving target nature of the best-in-class performance indicators. It also allows identifying targets that are realistic for a given type of manufacturing. It may not be realistic to have a manufacturer in a highly capital and materialintensive industry such as semiconductor manufacturing to set as targets the indicators achieved by a company involved in light mechanical assembly work. The class may be further refined by geography within an industry sub-group since geographical location may have a large influence on energy usage particularly due to heating and cooling costs for the manufacturing facility in industries where the manufacturing processes themselves are not energy intensive.

\section{RESEARCH AND IMPLEMENTATION CHALLENGES}

Implementation of a sustainable manufacturing maturity model will comprise two iterative stages, the assessment using the model and the improvement efforts to move towards the next level. The research and implementation challenges can be viewed with respect to the two stages.

The concept of the sustainable manufacturing maturity model is proposed based on existing standards and relatively easy to measure indicators to allow quick assessment. There are few research challenges for this stage. Assessment for higher levels in the proposed concept involves comparison with similar manufacturers, and that could pose a challenge. It is very likely that even similar manufacturers have different ranges of products being manufactured in their factories, thus making the task of comparison on a facility basis difficult. Research efforts may be needed to define steps to adjust the indicators for a fair comparison between facilities that make some but not all the same products. Analytical approaches such as Data Envelopment Analysis (DEA) may potentially be applicable for identification of peers within a larger group of similar manufacturers. DEA is a nonparametric method that utilizes linear programming to identify most efficient performers based on a defined set of inputs and outputs (Charnes, Cooper, and Rhodes, 1978). The identified efficient performances are used to define an efficiency frontier, which in turn is used to benchmark the performance of all producers.

Another research challenge is posed by the proposed use of multiple indicators for comparison for the best-in-class determination at level IV of the concept. A company might do better on some indicators while worse on other indicators than others. A potential method to solve this challenge is to develop weighting approaches that combine the indicators into a single index. However, such methods are open to the criticism that the selections of weights reveal "a high degree of arbitrariness" (Böhringer and Jochem, 2006). An industry association or a consortium may have to agree on a set of weights that are 
acceptable to everyone. Alternatively, DEA may be used for automatic generation of weights that are considered fair to everyone.

There are a few research areas that should be addressed to help manufacturers at the second implementation stage, that is, the stage of executing efforts to improve the sustainability of their operations and increase their maturity level. The first stage of implementation of a model based on the proposed concept will allow manufacturers to assess their level and, more importantly, will help motivate them to improve their maturity level for sustainable manufacturing. As mentioned in the previous section, once motivated the manufacturers may be able to utilize lean manufacturing practices for initial improvements. Deeper understanding of the process and product interactions and behavior may be required for further improvements. The research challenges lie in identifying approaches for developing "deeper" understanding and using such understanding for substantial improvements on the selected sustainability indicators. Data analytics may be needed to understand the factors that impact the selected indicators and the relationships between the factors and the indicators to be able to devise ways to improve the performance. Further predictive analytics may be needed to test out the alternative approaches for improving the performance and understanding their impact on all critical aspects of operations. Manufacturers would want to ensure that the desired improvements on the selected indicators do not have negative impact on other performance measures. They also would want to ensure that the anticipated performance improvements will be assuredly achieved. Thus, research challenges for supporting manufacturers in improving sustainability while not hurting other performance measures include data analytics and performance assurance.

Major implementation challenges for the proposed concept for a maturity model include identifying a group of similar manufacturers as benchmarking partners for sustainable manufacturing indicators and identifying and documenting the best in class performance as targets. The discussion in the previous section recommended identifying benchmarking partners directly or via trade associations. However, even within the same industry sub-group, possibly identified by North American Industry Classification System (NAICS) code, it can be difficult to find a manufacturing facility that has exactly the same range of products as another. An alternate way of identifying other similar manufacturers is via Product Category Rule (PCR) groups being developed under auspices of the International Environmental Product Declarations (EPD) System (International EPD System, 2013). The PCRs are being developed to support definition of EPDs of identified product categories. The intent for defining PCRs is to allow comparison of EPDs within the same categories similar to our intent of comparison of indicators for the sustainable manufacturing maturity model. Only a few PCRs are available as of the writing of this report. Hence, in the immediate future, a manufacturer may opt to develop a consortium of similar manufacturers. For the longer term, the organization may want to work with the International EPD System to develop a PCR to gain access to a larger group of manufacturers with similar products and better benchmarks for the improving sustainable manufacturing. Such an effort will also help in environmental labeling of products as that is the primary objective of International EPD System. The proposed indicators, that is, material, energy, and water intensity, require determining the consumption of these resources for the facility and the corresponding value added. The resource consumption should in general be easy to determine for a manufacturing facility. However, the value added may require some digging into financial and 
operational data. Corporations do declare value added in annual reports, but those are based on high level data for the entire organization. Once a company identifies that one of these indicators appears to be high, it will require delving into the details of products and the corresponding processes used to determine the product-process combinations that have larger resource consumption than others. Identifying energy and water consumption by individual product-process combinations can be quite challenging and may require installation of new measurement equipment and/or procedures.

\section{CONCLUSION}

There is a growing body of academic and professional literature for assessing the progress of organizations towards sustainable manufacturing. Most of the literature is at a high level and addresses a number of aspects beyond manufacturing operations. This effort proposed a concept for a model that is focused on assessing the maturity of sustainable manufacturing efforts of manufacturing operations at specific facilities. It is proposed that the concept be enhanced with input from stakeholders to arrive at a generic sustainable manufacturing maturity model with the desired set of levels, indicators, and standards for use at the lower levels. The model can then be further enhanced for use by specific industry groups with addition of domain-specific standards and metrics corresponding to the indicators in the generic model. The version of the generic model approved by stakeholders may be further developed for consideration as an international standard.

The proposed concept is based on learning from some of the existing maturity models that have much larger scopes. In particular, the proposed concept uses the approach of assessing compliance and infrastructure for collecting the indicators at lower maturity levels and using actual indicators at higher levels of maturity for assessing the progress. Such approaches have been used by some of the other efforts discussed in section 2.

The proposed concept builds on prior work, in particular ISO standards, for ensuring compliance and use of credible approaches for collecting the indicators that are used for assessing the sustainable manufacturing maturity. Use of such standards is proposed to ensure that the indicators can be compared across similar manufacturers to identify best in class performers and realistic targets for improving the maturity. Implementation of the proposed concept of maturity model requires addressing the challenges of identifying similar manufacturers and comparison using multiple indicators at the assessment stage and data analytics and performance assurance at the stage of planning and executing improvement efforts. All of the preceding challenges are potential areas for future research. Another direction of future work is to link the sustainability performance of an individual manufacturing company or location to corresponding performance of the supply chain(s) the company participates in. Graedel and Allenby (2002) support defining a hierarchy with indicators at one level linking clearly to levels above and below. The effort to develop supply chain level sustainability indicators and associated maturity model will be rather complex and faces multiple challenges. One manufacturer may be involved in multiple supply chains and may have to track different sets of indicators selected by the different supply chains. The manufacturers may receive conflicting inputs from the different supply partners. Supply chains may extend across different industrial sectors, for example, chemical manufacturers may supply bulk materials to automotive manufacturers. It can be a challenge to identify 
indicators that can be linked in such supply chains extending across sectors. Industry organizations involving multiple supply chain partners have to come together to address such challenges and develop hierarchy of indicators to improve the sustainability of entire supply chains.

\section{DISCLAIMER}

Some commercial products may have been identified in this paper. This does not imply a recommendation or endorsement of the products by the authors or NIST, nor does it imply that such products are necessarily the best available for the purpose.

\section{ACKNOWLEDGMENTS}

This paper has improved significantly from the input by reviewers, especially from the technical review and detailed comments provided by Mark Palmer of NIST.

Sanjay Jain's work on this effort has been sponsored under the cooperative agreement no. 70NANB13H158 between the National Institute of Standards and Technology (NIST) and George Washington University. The work described was funded by the United States Government and is not subject to copyright.

\section{REFERENCES}

Böhringer, C., and Jochem, P. 2006. Measuring the immeasurable: a survey of sustainability indices, ZEW Discussion Papers, No. 06-73. Available on-line:

http://www.econstor.eu/dspace/bitstream/10419/24527/1/dp06073.pdf.

British Standards Institution, 2013. BS 8900-1:2013 Managing sustainable development of organizations - Part 1: Guide. ISBN 9780580763403.

Cagnin, C., and Loveridge, D. 2011. "A business framework for building anticipatory capacity to manage disruptive and transformative change and lead business networks towards sustainable development." Fourth International Seville Conference on Future-Oriented Technology Analysis (FTA), FTA and Grand Societal Challenges - Shaping and Driving Structural and Systemic Transformations, Seville, 12-13 May 2011.

Ceres, 2010. The $21^{\text {st }}$ Century Corporation: The Ceres Roadmap for Sustainability. Boston, MA: Ceres. Available on-line: http://www.ceres.org/resources/reports/ceres-roadmap-to-sustainability-2010/view.

Charnes, A., W. Cooper, \& E., Rhodes (1978) "Measuring the efficiency of decision-making units," European Journal of Operational Research 2:429-444.

CMU, 2002. Capability Maturity Model Integration (CMMI). In: CMMISM for System Engineering, Software Engineering, Integrated Product and Process Development, and Supplier Sourcing (CMMISE/SW/IPPD/SS), Carnegie Mellon University, Pittsburgh, PA. 
Consolandi, C., Innocenti, A., and Vercelli, A. 2009. "CSR, rationality and the ethical preferences of investors in a laboratory experiment." Research in Economics 63(4):242-252.

Crosby, P.B. 1979. Quality is Free: The Art of Making Quality Certain. New York: Penguin.

Dornfeld, D. 2014. "Moving towards Green and Sustainable Manufacturing." International Journal of Precision Engineering and Manufacturing - Green Technology, January 2014, 1(1):63-66.

EPA, 2006. Life Cycle Assessment: Principles and Practice. National Risk Management Research Laboratory, Office of Research and Development, U.S. Environmental Protection Agency, Report EPA/600/R-06/060.

European Commission, 2004. EMAS Energy Efficiency Toolkit for Small and Medium Sized Enterprises. ISBN 92-894-8196-X. Accessed June 27, 2013 via: http://ec.europa.eu/environment/emas/pdf/general/energyeff en.pdf.

European Commission, 2007. EMAS Easy for Small and Medium Enterprises. Accessed June 27, 2013 via: http://www.emas-easy.eu/.

European Commission, 2008. Environment Fact Sheet: Sustainable consumption and production - $a$ challenge for us all. No. KH-81-08-181-EN-D. Accessed June 27, 2013 via:

http://ec.europa.eu/environment/eussd/pdf/brochure.pdf.

European Commission, 2009. REGULATION (EC) No 1221/2009 OF THE EUROPEAN PARLIAMENT AND OF THE COUNCIL of 25 November 2009 on the voluntary participation by organisations in a Community eco-management and audit scheme (EMAS). Accessed June 27, 2013 via: http://eurlex.europa.eu/LexUriServ/LexUriServ.do?uri=OJ:L:2009:342:0001:0045:EN:PDF.

Fiskel, J., Eason, T., and Frederickson, H. 2012. A Framework for Sustainability Indicators at EPA. National Risk Management Research Laboratory, Office of Research and Development, U.S. Environmental Protection Agency, Report EPA/600/R/12/687. Accessed July 16, 2013 via: http://epa.gov/sustainability/docs/framework-for-sustainability-indicators-at-epa.pdf.

GEMI, 2012. GEMI Local Water Tool (LWT) Version 1.0. Global Environmental Management Initiative. Accessed February 3, 2014 via:

http://www.gemi.org/localwatertool/pdf/GEMI_LWT_sample_finalMar12.pdf

Graedel, T.E., and Allenby, B.R. 2002. "Hierarchical Metrics for Sustainability." Environmental Quality Management. Winter 2002: 21-30.

GRI, 2013. Global Reporting Initiative. Accessed July 10, 2013 via:

https://www.globalreporting.org/Pages/default.aspx.

Hiller, H., Mills, V. , and Reyna, E., 2011. "Breaking Down Barriers to Energy Efficiency." Environmental Defense Fund. Accessed June 27, 2013 via: 
http://business.edf.org/sites/business.edf.org/files/Breaking\%20Down\%20Barriers\%20to\%20Energy\%20 Efficiency\%20-\%20April\%202012.pdf.

Horst, 2014. Personal communication with John Horst, National Institute of Standards and Technology, serving as a member of MESA Metrics Working Group.

IGEL, June 2012. Greening the Supply Chain: Best Practices and Future Trends, Initiative for Global Environmental Leadership (IGEL), The Wharton School, University of Pennsylvania. Accessed July 9, 2013 via: http://knowledge.asb.unsw.edu.au/article.cfm?articleid=1616.

International EPD System, 2013. Product Category Rules (PCRs). Accessed July 16, 2013 via: http://www.environdec.com/en/Product-Category-Rules/.

IRI, 2012. Sustainability Maturity Assessment Tool. Industrial Research Institute. Accessed July 12, 2013 via:

http://www.iriweb.org/Public Site/Navigation/Library/Public Documents/Tools/Sustainability Maturity Assessment Tool.aspx.

ISO 9001: 2000. Quality management systems — Requirements. International Organization for Standardization, Geneva, Switzerland.

ISO 14001:2004. Environmental Management Systems - Requirements with Guidance for Use. International Organization for Standardization, Geneva, Switzerland.

ISO 14001:2004/Cor.1:2009. Environmental Management Systems - Requirements with Guidance for Use TECHNICAL CORRIGENDUM 1. Published 2009-07-15. International Organization for Standardization, Geneva, Switzerland.

ISO 14006:2011. Environmental Management Systems - Guidelines for Incorporating Ecodesign. International Organization for Standardization, Geneva, Switzerland.

Jain, S., Shao, G., Brodsky, A., and Riddick, F. 2013. "A Model-Based Continuous Improvement Methodology for Sustainable Manufacturing." In Proceedings of the2013 International Conference on Advances in Production Management Systems (APMS), Part I: 268-277. Springer 2013 IFIP Advances in Information and Communication Technology ISBN 978-3-642-41265-3.

KPMG, 2011. Corporate Sustainability: A Progress Report. KPMG International. Publication number : 314644. Publication date: April 2011.

Krajnc, D., and Glavič, P. 2003. "Indicators of sustainable production." Clean Technology Environmental Policy 5(3-4):279-288.

Lubin, D.A., and Esty, D.C., 2010. "The Sustainability Imperative." Harvard Business Review 88(5): 42-50.

Maier, A.M., Moultrie, J., and Clarkson, P.J., 2012. "Assessing Organizational Capabilities: Reviewing and Guiding the Development of Maturity Grids." IEEE Transactions on Engineering Management 59(1): 138159. 
Mani, M., Lyons, K., and Sriram, R. 2010. "Developing a Sustainability Manufacturing Maturity Model." In Proceedings from the IMS Summer School on Sustainable Manufacturing, 311-321.

MESA, 2010. Building a Manufacturing Transformation Strategy with ISA-95 Methods. White paper \#38. Manufacturing Enterprise Solutions Association (MESA). Available via:

https://services.mesa.org/resourcelibrary/showresource/fb22c0e4-321b-4e28-8314-95a2919ad53b.

MESA, 2014. Metrics Working Groups. Manufacturing Enterprise Solutions Association (MESA). Accessed February 7, 2014 via: http://www.mesa.org/en/committeeactivities/metricsworkinggroups.asp.

MTS, 2006. EMERGENCY SMaRTC Standard 4.0 Promoting Sustainable Product Achievement. Approved Consensus Standard 12-15-06. Editorial Changes 9-6-11. Institute for Market Transformation to Sustainability, Washington, DC.

OECD, 2011. OECD Sustainable Manufacturing Toolkit - Seven Steps to Environmental Excellence. Accessed August 5, 2013 via: http://www.oecd.org/innovation/green/toolkit/48661768.pdf.

Pojasek, R.B. 2007. “Introducing ISO 14001 III.” Environmental Quality Management 17(1):75-82.

Rashid, S.H.A., Evans, S., and Longhurst, P. 2008. "A comparison of four sustainable manufacturing strategies." International Journal of Sustainable Engineering, 1(3): 214-229.

Reefke, H., Sundaram, D., and Ahmed, M.D., 2010. "Maturity Progression Model for Sustainable Supply Chains." W. Dangelmaier et al. (Eds.): Advanced Manufacturing and Sustainable Logistics: 8th International Heinz Nixdorf Symposium (IHNS 2010), LNBIP 46:308-319. Berlin: Springer-Verlag.

Saco, R.M., 2008. "Maturity models inject new life." Industrial Management, July/August 2008, 11-15.

Senge, P., Carstedt, G., and Porter, P. 2010. "Innovating our way to the next industrial revolution." MIT Sloan Management Review 44(2):24-38.

Sikdar, S.K., 2003. "Sustainable Development and Sustainability Metrics." AIChE Journal, 49(8): 19281932.

Singh, R.K., 2008. "Developing a Composite Sustainability Index." Chapter 10 in Measuring Sustainable Production, OECD Sustainable Development Studies series, Organisation for Economic Co-operation and Development. (proceedings of an OECD workshop on Sustainable Manufacturing Production and Competitiveness held in Copenhagen, Denmark on 20-21 June 2007). Available on-line via: www. sourceoecd.org/energy/9789264044128

Smith, L., Ball, P., 2012. "Steps towards sustainable manufacturing through modelling material, energy and waste flows." International Journal of Production Economics 140:227-238.

UL, 2011. UL880: Standard for Sustainability for manufacturing organizations. First Edition. Underwriters Laboratories Inc. Accessed August 5, 2013 via: http://www.ul.com/global/documents/offerings/ULEnvironment/sqprogram/ul880 dec2011.pdf. 
UNDESA, 2010. Proposed Input to CSD 18 And 19 on a 10 Year Framework of Programmes on Sustainable Consumption and Production (10YFP On SCP). Revised Draft (7 April 2010). Marrakech Process Secretariat: United Nations Department of Economic and Social Affairs (UNDESA) and United Nations Environment Programme (UNEP). Accessed September 5, 2013 via: http://esa.un.org/marrakechprocess/pdf/Draft3 10yfp RevisedUNEP-UNDESA.pdf.

UNEP, 2010. Joint UNIDO-UNEP Programme on Resource Efficient and Cleaner Production in Developing and Transition Countries. United Nations Environment Programme. Accessed July 10, 2013 via: http://www.unep.org/resourceefficiency/Portals/24147/scp/cp/pdf/RECP\%20Programme\%20Flyer\%20 April\%202010.pdf.

UNSCD, 2012. Development of key environmental indicators and life cycle data for key product chains. RIO+20 United Nations Conference on Sustainable Development. Accessed July 10, 2013 via: http://www.uncsd2012.org/index.php?page=view\&type=1006\&menu=153\&nr=491\#deliverables.

Valdivia, S. 2012. "Life Cycle Management Capability Framework for Business Training for Supplier SelfAssessment." UNEP/SETAC Life Cycle Initiative workshop on Life Cycle Assessment and Management. 1st Indian Life Cycle Assessment \& Management Conference, August 22-23 2012, New Delhi, India. Presentation accessed July 10, 2013 via: http://www.indialca.com/pdfs/ILCM-2012-CMM-training.pdf.

Van Marrewijk, M. 2003. "Concepts and Definitions of CSR and Corporate Sustainability: Between Agency and Communion." Journal of Business Ethics 44(2/3): 95-105.

WBCSD, 2000. Measuring Eco-efficiency: A Guide to Reporting Company Performance. World Business Council for Sustainable Development. Accessed July 10, 2013 via:

http://www.gdrc.org/sustbiz/measuring.pdf.

Finley, T., Leathers, G., and Zhang, H.X. 2008. Use of the WBCSD Global Water Tool to Assess Global Water Supply Risk and Gain Valuable Strategic Perspective. In Proceedings of the Water Environment Federation - WEFTEC 2008, p. 4375-4383.

WRI/WBCSD, 2011. Product Life Cycle Accounting and Reporting Standard. World Resources Institute and World Business Council for Sustainable Development. ISBN 978-1-56973-773-6.

Weyns, K., \& Höst, M. (2012). "Evaluation of a Maturity Model for IT Dependability in Emergency Management." International Journal of Information Systems for Crisis Response and Management (IJISCRAM), 4(1), 47-63.

Hao Zhang, H., and Haapala, K.R. 2014. "Integrating sustainable manufacturing assessment into decision making for a production work cell." Journal of Cleaner Production, In Press, Corrected Proof, available online 22 January 2014. DOI: http://dx.doi.org/10.1016/j.jclepro.2014.01.038. 